\title{
EXPLORING SOCIALLY SHARED REGULATED LEARNING IN PBL USING GROUP DIGITAL LEARNING DIARIES: A STUDY DESIGN
}

\section{Thea MORGAN}

University of Bristol, United Kingdom

\begin{abstract}
A research study design is presented. The purpose of the study is to explore the potential of group digital learning diaries for capturing, formatively assessing, and developing socially shared regulated learning using three central aspects of regulated learning: conceptions of knowledge, conceptions of learning, and strategies for monitoring and regulating learning. In contrast to self-regulated learning, there has been little research into socially shared regulated learning, despite common agreement in the field that it is needed. Socially shared regulated learning is relevant to group performance during active learning in collaborative contexts, such as group PBL. The outcomes of the research outlined therefore have the potential for genuine impact on understanding in socially shared regulated learning, as well as to provide innovation in teaching and learning practices.
\end{abstract}

\section{Keywords: Socially shared regulated learning, reflective learning diaries, project-based-learning}

\section{INTRODUCTION}

Today's student of engineering design must develop skills as a lifelong learner - to keep up with the rapid expansion of knowledge and transferable skills needed to succeed in fast evolving technological industries. The future of engineering design education therefore centres on active learning in authentic contexts [1]. Creating learning environments in which students take control of their own learning, construct and co-construct new knowledge and skills for themselves in relation to 'real-world' complex subject matter and are able to transfer what they have learned to new problems and settings [2]. Active learning is underpinned by self-regulated learning (SRL) skills, such as assessing the demands of a task, setting goals for learning, selecting suitable resources, selecting suitable methods for learning, and evaluating progress [3]. These skills relate to the cognitive, metacognitive, behavioural, motivational, and emotional/affective aspects of learning [4]. Metacognition is the awareness or analysis of one's own thinking and learning, such as when learners plan, monitor, evaluate and make changes to their learning behaviours. Teaching and learning approaches which support the development of SRL skills are studentcentred and focus on sense-making, formative assessment, and reflection. Approaches such as projectbased-learning (PBL). Students engagement in SRL, however, is strongly influenced by previous learning experiences and by their beliefs about the nature of knowledge and its acquisition [5], [6]. Engineering design students tend towards a positivistic view of knowledge and learning, which is at odds with the constructivist learning paradigm of active, student centred PBL, in which knowledge is constructed and co-constructed through reflection on experience [6]. Active learning approaches must go beyond reflecting on content, to reflecting on student learning and conceptions of knowledge [7]. Whilst many studies have considered SRL processes at an individual level [4], the role of SRL during collaborative learning activities remains unclear. There has been little research into socially shared regulated learning (SSRL), despite common agreement in the field that it is needed [8]. It is therefore the aim of the research presented here to investigate ways in which to capture, formatively assess, and develop SSRL skills, during collaborative PBL, using group digital learning diaries. Learning diaries are shown to be an effective method for capturing SRL processes, as well as formatively assessing them [2]. They have also been shown to facilitate the further development of students' SRL skills [9]. 


\section{BACKGROUND}

\subsection{Socially shared regulated learning}

There is an abundance of literature published on self-regulated learning and its links to motivation and academic achievement. For example, [10], [11], [4]. However, the concept of socially shared regulation of learning (SSRL) has only recently emerged. Panadero and Järvelä [12] describe how SSRL occurs when groups 'regulate together as a collective, such as when they construct shared task perceptions or shared goals [...] co-construct plans or align monitoring perceptions to establish a shared evaluation of progress' through 'shared metacognitive monitoring and control of motivation, cognition and behaviour'. The emergence of SSRL as a concept has coincided with a shift in teaching practices, away from the didactic, to more active, collaborative learning approaches. Research in SSRL however is still rather limited. There have been a few notable studies, such as Volet et al. [13] who explore the role of regulatory mechanisms in self- and social regulation models, Hadwin et al. [8] who contrast social aspects of self-regulated learning, co-regulated learning, and socially shared regulation of learning, and Järvelä et al. [14] who explore ways to enhance socially shared regulation in collaborative learning groups. Panadero and Järvelä [14] have published a narrative review on SSRL looking at 13 empirical studies, concluding that SSRL does indeed contribute to group performance. They noted that most of the SSRL research thus far has focused on characterising SSRL phenomena, mostly through qualitative video-recorded observation data. The article discusses the need for the field to move forward, using a wider variety of research approaches to explore the best conditions to capture, formatively assess, and develop SSRL. Given the limited availability of published research on SSRL, the remainder of the review of the literature will focus more generally on SLR, with the assumption that the findings are also broadly relevant to SSLR.

\subsection{Reflective learning diaries}

Research has shown that reflective learning diaries can reveal insights into students' cognitive, metacognitive, social, and motivational strategies for SRL, which are not easily captured through observation or other means [2]. Capturing student SRL is important, to develop an understanding of active learning in more depth for the purposes of research and to improve teaching and learning practices. The focus of engineering education research is typically on the outcomes of courses or learning interventions, rather than on the learning journey that students take along the way. Reflective learning diaries allow researchers to gather data about learning over time, with high ecological validity because data is gathered from students in their natural learning environment. In reflective learning diaries, the mechanism of reflection occurs through the process of representing learning in written form and reading this representation back. Learning diaries also enable the upgrading of learning, from surface to deep learning 'where unconnected areas of meaning cohere, and deeper meaning emerges' [15]. They also enable the learner to understand their own learning process, to increase personal ownership of learning, to explore the self, personal constructs of meaning, and understand one's view of the world [15]. Learning diaries can be structured to varying degrees to guide the process of reflection, including prompts, exercises, or guidance about issues to reflect on. Reflective learning diaries can therefore be seen to facilitate development of self-regulated learning skills in active learning environments such as PBL.

Reflective learning diaries can also be used for formative assessment of SRL [2]. Formative assessment is not an instrument of measurement, it is a two-way process to support and develop student learning through feedback and scaffolding. Feedback should be treated as a dialogue that enables students to become self-regulated learners, instead of simply as information to be transmitted directly from teacher to student [16]. Teachers and students can gain crucial information about the learning process through regular formative assessment, and to adjust learning behaviours, strategies, and scaffolding accordingly. But to be effective, students must be actively involved in the construction of meaning around their learning, and feedback should be situated within the context of students' own experience and reflections. By integrating the feedback into other course activities, students are further encouraged to become selfregulated learners and to develop more contextual ways of knowing [2].

\subsection{Students' epistemological beliefs}

Epistemological beliefs relate to conceptions of knowledge and how knowledge can be created or acquired [6]. They play an important role in learning, acting as a kind of gateway to new knowledge. 
During active learning, students do not learn directly from experience, they learn from their 'perceptions' of that experience. The prior learning, knowledge, and epistemological beliefs of students have a strong influence on the outcomes of active learning approaches such as PBL. Moon [15] suggests that educators involved in active learning 'need to pay more attention to the prior experiences of the learner that will affect their initial perceptions of the experience'. This has significant implications for engineering design students undertaking PBL, whose perceptions will be strongly influenced by prior engineering science learning and its related positivistic worldview [6]. While active learning environments can encourage development of SRL, it cannot be assumed that all students will engage in regulated learning if their perceptions of knowledge and learning are not in accord with the constructivist learning paradigm of PBL. Therefore, it is important to be able to capture, assess, and develop students' epistemological beliefs during active learning, to facilitate regulated learning in collaborative PBL. A study by Wallin and Adawi [2] found that during active learning some students had an absolute way of knowing and focus on learning outcomes, whilst other students had a more contextual way of knowing and focus on the learning process, demonstrating the importance of students' epistemological beliefs in development of SRL. Current approaches to formative assessment in PBL do not reveal the conflicting learning paradigms of engineering design education, and therefore limit the ability of students to reflect on their own active learning. Students effectively experience an 'epistemological block to reflection' [6]. Reflective learning diaries could be used to capture and assess epistemological beliefs and conceptions of learning over time, and through situated dialogic feedback reveal to students the differing learning paradigms of design and engineering science, enabling deeper reflection and metacognition, and therefore development of SRL.

\subsection{Conceptual framework of research}

Wallin and Adawi [2] define three central aspects of SRL: conceptions of knowledge, conceptions of learning, and strategies for monitoring and regulating learning.

Table 1. Three central aspects of SRL (Adapted from Wallin \& Adawi [2])

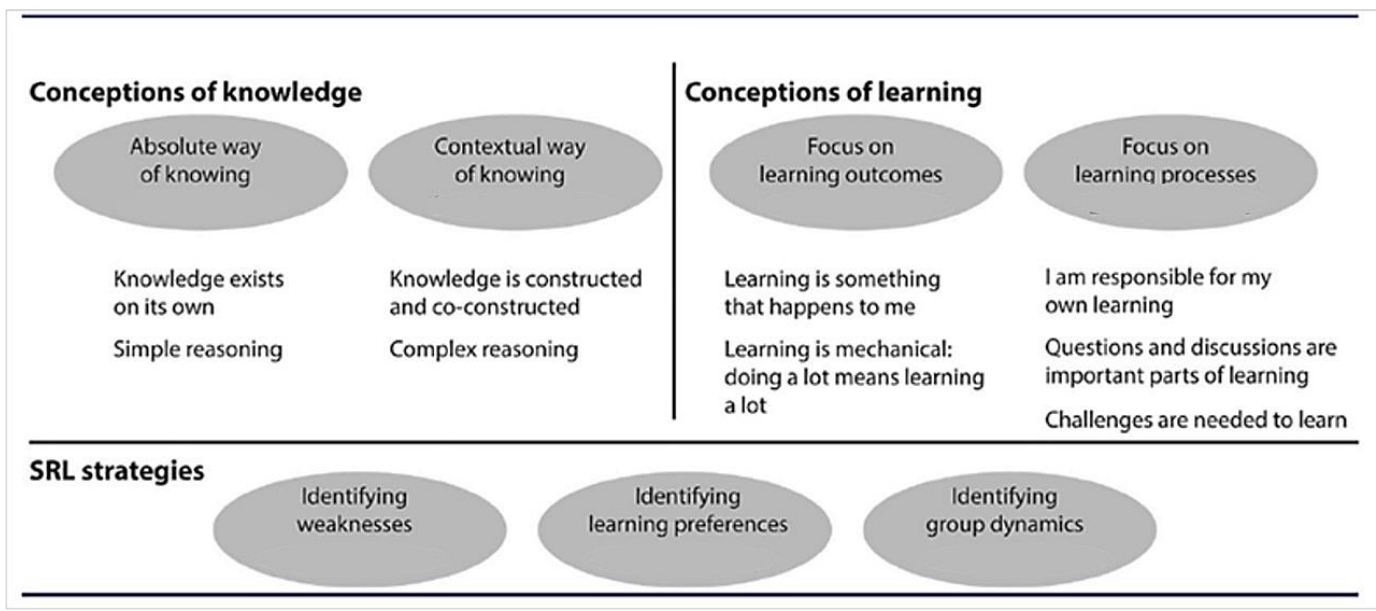

Conceptions of knowledge relate to the students' epistemological beliefs, that is, what knowledge is and how it is created. Conceptions of learning relate to how the students conceptualise learning and their role in the learning process. Strategies for monitoring and regulating learning relate to how students use cognitive, metacognitive, motivational, and behavioural processes to plan, monitor, and evaluate their learning. See table 1. The research design presented and discussed in the remainder of the paper uses these three central aspects of SLR as a conceptual framework, again with the assumption that these concepts are as applicable to SSLR as to SLR.

\section{DESIGN OF AN EXPLORATIVE RESEARCH STUDY}

To investigate ways in which to capture, formatively assess, and develop SSRL skills during PBL using group digital learning diaries, a two-year research study has been designed and is now underway. The design of the research study is detailed below. 


\subsection{Study context}

The focus of the study is a Y2 undergraduate engineering design methods course at the University of Bristol. The 5 ects-credit course, which uses a group project-based-learning approach, runs for 24 weeks across the academic year. The study will involve two cohorts of students, each taking the course in consecutive years. The first cohort of students, consisting of 29 individuals ( 10 women and 19 men) has been divided into 6 mixed gender/mixed ability project groups (5 groups of 5 students, and 1 group of 4 students). The subsequent cohort is expected to be of a similar size, and gender/ability mix, and will be allocated into 6 groups in a similar way. The unit, 'Design Methods 2', introduces students to different approaches to the conceptual design process, and associated design methods, tools and techniques, including systematic design, human-centred design, and social innovation design. The unit also looks more broadly at the nature of design and design thinking, in a socio-cultural and global context, as well as the nature and experience of learning to design. The unit uses a 'flipped learning' approach to content, with all learning materials - in the form of slides, videos, audio, weblinks, and documents - posted online a week before each session. The weekly two-hour design sessions focus on practical group work, based around three consecutive mini projects, in which the students have a chance to try out different design frameworks, methods and tools. Teaching takes place in a new technology enabled design studio, equipped with 'pods' for group design work. Each pod features a leaf-shaped table for six students, a large display screen, and a Microsoft Surface Studio. Each pod is linked to the main lectern, which itself has a Surface Studio and main display screen. From here all six pods can be controlled, either in 'teaching mode' for lecturing (all pods show the lecture slides), or 'collaborative mode' for group work (each pod displays its own Surface Studio content). The Surface Studios are installed with digital sketching software allowing students to sketch directly onto the screen, providing the possibility of group interactive sketching and design work. They also enable the keeping of group digital design logs, where all project information can be recorded, manipulated, displayed, and accessed easily as a group. The leaf-shaped tables also help facilitate this collaborative work, by allowing groups to sit facing each other, whilst still having a view of the pod's display screen, Surface Studio, and main lectern.

\subsection{Research design}

The research is designed to explore the potential of group digital learning diaries for capturing, formatively assessing, and developing three central aspects of SSRL: conceptions of knowledge, conceptions of learning, and strategies for monitoring and regulating learning. An inductive qualitative research design is being used, involving a case study approach and thematic analysis of primary data [17]. Two complete cycles of diary design/refinement, data gathering, data analysis and interpretation/final evaluation are being carried out over 24 months (see table 2).

Phase 1: A prototype group digital learning diary has been designed and is currently in use as a data gathering tool to explore how aspects of SSRL can be captured using this approach. The structured diary design, including reflective questions and prompts, is based on that developed by Wallin \& Adawi [2] (see next section). The digital nature of the diaries is intended to better facilitate group entries, through use of large touch-screen tablets, and make it possible for students to record information in a variety of formats e.g. sketches, images, video, audio, and computer-aided design (CAD) models. Evernote is used as the online platform for the digital diaries, which student groups access through the Surface Studio tablets, part of their technology enabled 'pods'. The outcome of this phase is a tool for collecting primary data relating to SSRL processes in collaborative learning environments.

Phase 2: Qualitative data will be gathered over the course of the Design Methods 2 unit (24 teaching weeks). The groups of students will be required to write in their group learning diary together at the end of each weekly 2-hour design session. Collectively these group diaries will form a rich dataset. At the end of the unit, a focus group will also be conducted with each student group, using semi-structured questions. These focus groups will be audio-recorded and transcribed, forming an additional dataset. The outcome of this phase will be two primary data sets relating to capturing SSRL processes in collaborative learning environments.

Phase 3: The two primary data sets will be inductively analysed and interpreted using a thematic analysis approach within the conceptual framework of; conceptions of knowledge, conceptions of learning, and strategies for monitoring and regulating learning. According to Braun et al. [17] 'thematic analysis is a method for identifying, analysing, and reporting patterns (themes) within data'. The outcome of this phase will be identification of key themes to emerge from the data, relating to a qualitative understanding of SSRL processes in collaborative learning environments. 
Phase 4: The group digital learning diary will be refined/redesigned, in response to the themes identified in phase 3. The purpose of the refined diary will be to provide a means, not only to capture, but formatively assess and develop SSRL skills in this context. The intention is that through this formative assessment, SSRL skills will be further developed. The outcome of this phase will be an education tool for formative assessment of SSRL skills development. The tool also serves as a means collecting richer primary research data relating to SSRL processes.

Phase 5: Qualitative data will again be gathered over the course of the subsequent Design Methods 2 unit (24 teaching weeks), during weekly group design work. At the end of the unit, further focus groups will be held with each student group, using semi-structured questions. The outcome of this phase will be two rich primary data sets relating to capturing, formatively assessing, and developing SSRL processes in collaborative learning environments.

Phase 6: A final round of data analysis and interpretation, using thematic analysis and the conceptual framework, will be carried out using the two further datasets. Themes will be identified and described, and a final qualitative evaluation of the whole two-year study will be carried out. The evaluation method will involve qualitatively comparing the series of research outcomes to the original research objectives. The outcomes of this phase will be identification of key themes relating to a qualitative understanding of how SSRL processes can be captured, formatively assessed and developed in collaborative learning environments using group digital learning diaries. Also, an evaluation of the success of the study, including limitations and further work.

Table 2. Study phases, research activities, outputs, and timescales

\begin{tabular}{|c|c|c|c|}
\hline $\begin{array}{l}\text { Study } \\
\text { phase }\end{array}$ & Research Activity & Research outcome(s) & $\begin{array}{l}\text { Study } \\
\text { months }\end{array}$ \\
\hline Phase 1 & $\begin{array}{l}\text { Design of an exploratory prototype } \\
\text { group digital learning diary }\end{array}$ & $\begin{array}{l}\text { A tool for collecting primary data relating to SSRL processes in } \\
\text { collaborative learning environments. }\end{array}$ & $1-2$ \\
\hline Phase 2 & $\begin{array}{l}\text { Qualitative data gathering from } \\
\text { group diary entries and focus groups. }\end{array}$ & $\begin{array}{l}\text { Two primary data sets relating to capturing SSRL processes in } \\
\text { collaborative learning environments. }\end{array}$ & $3-9$ \\
\hline Phase 3 & $\begin{array}{l}\text { Qualitative data analysis and } \\
\text { interpretation using theme analysis }\end{array}$ & $\begin{array}{l}\text { Identification of key themes to emerge from the data, relating to } \\
\text { a qualitative understanding of SSRL processes in collaborative } \\
\text { learning environments. }\end{array}$ & $10-12$ \\
\hline Phase 4 & $\begin{array}{l}\text { Refinement of group digital learning } \\
\text { diary for formative SSRL } \\
\text { assessment }\end{array}$ & $\begin{array}{l}\text { An education tool for formative assessment of SSRL skills } \\
\text { development. The tool also serves as a means of collecting } \\
\text { richer primary research data relating to SSRL processes. }\end{array}$ & $13-14$ \\
\hline Phase 5 & $\begin{array}{l}\text { Qualitative data gathering, from } \\
\text { group diary entries and focus groups. }\end{array}$ & $\begin{array}{l}\text { Two rich primary data sets relating to capturing, formatively } \\
\text { assessing, and developing SSRL processes in collaborative } \\
\text { learning environments. }\end{array}$ & $15-21$ \\
\hline Phase 6 & $\begin{array}{l}\text { Qualitative data analysis, } \\
\text { interpretation, and final evaluation }\end{array}$ & $\begin{array}{l}\text { Identification of key themes relating to how SSRL processes can } \\
\text { be captured, formatively assessed and developed in } \\
\text { collaborative learning environments. An evaluation of the study } \\
\text { against the original aims and objectives. }\end{array}$ & $22-24$ \\
\hline
\end{tabular}

\subsection{Reflective learning diary design}

The design of the reflective learning diary is based on that outlined by Wallin \& Adawi [2]. Four general categories of prompts are used to encourage reflection on different levels each week: 1) what has happened, 2) how did we approach the situation, 3) why is it important, and 4) how did we learn from it. The reflection topics are grounded within the weekly activities the students are engaged in. The prompts focus both on general learning experiences e.g. "what was the greatest learning challenge this week?', as well as on the specific phase of the project in each week e.g. 'how did you go about choosing viable concept combinations as part of morphological analysis?' By also using prompts that are both forward and backward looking in time, the students are encouraged to reflect on their planning for impending tasks, monitor their learning and behaviour, and evaluate their performance on completed tasks. A new diary entry page containing relevant prompts is added to the group digital diaries each week. The students' access these in groups through their pods during the last 15 mins of their 2-hour course session. They discuss and answer the prompts as a group.

\section{DISCUSSION \& CONCLUSIONS}

The intended outcomes of the research study include a qualitative understanding of how SSLR processes can be captured, formatively assessed, and developed in collaborative learning environments, as well as a practical tool for formative assessment for use in collaborative learning courses. The study therefore 
provides a vehicle for achieving higher academic standards of active learning within collaborative, engineering design education. The research focuses on formative assessment of SSRL using dialogic feedback based on students' epistemological beliefs, helping to create a cyclical relationship between learning, assessment, and feedback and improving students understanding of their own learning experience. The innovative learning tool can help support development of SSRL, equipping students with skills and an attitude to learning that will benefit them in any future collaborative work and helping them to develop as self-sufficient and independent learners. The research should also enable students to make the most out of state-of-the-art collaborative learning spaces, by facilitating the effective use of embedded collaborative learning technology. The digital group learning diaries are e-learning tools which have the potential to help teaching staff optimise their delivery of high-quality teaching, assessment and feedback. The proposed research supports the development of lifelong transferable skills and the knowledge and understanding needed for engineering students to succeed in rapidly evolving technological industries, through collaborative work on authentic problem-based challenges.

The results of the research study will be published in a future paper.

\section{REFERENCES}

[1] Graham, R. (2018). The global state of the art in engineering education. Massachusetts Institute of Technology, Cambridge, MA, USA.

[2] Wallin, P., \& Adawi, T. (2018). The reflective diary as a method for the formative assessment of self-regulated learning. European Journal of Engineering Education, 43(4), 507-521.

[3] Pintrich, P. R., and A. Zusho. 2007. "Student Motivation and Self-Regulated Learning in the College Classroom." The Scholarship of Teaching and Learning in Higher Education: An Evidence-based Perspective, 731-810. Dordrecht: Springer.

[4] Panadero, E. (2017). A review of self-regulated learning: six models and four directions for research. Frontiers in psychology, 8, 422.

[5] Muis, K. A. (2007). The role of epistemic beliefs in self-regulated learning. Educational Psychologist, 42(3), 173-190.

[6] Morgan, T, 2019, 'Enabling meaningful reflection within project-based-learning in engineering design education'. in: Dirk Schaefer, Claudia Eckert, Graham Coates (eds) Design Education Today: Technical Contexts, Programs and Best Practices. Springer

[7] Vos, H., and E. de Graaff. 2004. "Developing Metacognition: a Basis for Active Learning." European Journal of Engineering Education 29 (4): 543-548.

[8] Hadwin, A. F., Järvelä, S., \& Miller, M. (2011). Self-regulated, co-regulated, and socially shared regulation of learning. Handbook of self-regulation of learning and performance, 30, 65-84.

[9] Babapour, M., Rahe, U., \& Pedgley, O. 2012. "The Influence of Self-reflective Diaries on Students Design Processes." In DesignEd Asia Conference, Hong Kong, 1-13.

[10] Zimmerman, B. J., \& Schunk, D. H. (Eds.). (2001). Self-regulated learning and academic achievement: Theoretical perspectives. Routledge.

[11] Winne, P. H., \& Hadwin, A. F. (2008). The weave of motivation and self-regulated learning. Motivation and self-regulated learning: Theory, research, and applications, 2, 297-314.

[12] Panadero, E., \& Järvelä, S. (2015). Socially shared regulation of learning: A review. European Psychologist.

[13] Volet, S., Vauras, M., \& Salonen, P. (2009). Self-and social regulation in learning contexts: An integrative perspective. Educational psychologist, 44(4), 215-226.

[14] Järvelä, S., Kirschner, P. A., Panadero, E., Malmberg, J., Phielix, C., Jaspers, J., ... \& Järvenoja, H. (2015). Enhancing socially shared regulation in collaborative learning groups: designing for CSCL regulation tools. Educational Technology Research and Development, 63(1), 125-142.

[15] Moon, J. A. (2013). Reflection in learning and professional development: Theory and practice. Routledge.

[16] Carless, D., Salter, D., Yang, M., \& Lam, J. (2011). Developing sustainable feedback practices. Studies in higher education, 36(4), 395-407.

[17] Braun, V., Clarke, V., Hayfield, N., \& Terry, G. (2019). Thematic analysis. Handbook of Research Methods in Health Social Sciences, 843-860. 